\title{
Rapid Data Delivery System (RDDS)
}

\author{
Rocky Mountain Geographic Science Center
}

\section{Rapid Data Access for Emergency Response}

Since the start of the active 2000 summer fire season, the U. S. Geological Survey (USGS) Rocky Mountain Geographic Science Center (RMGSC) has been actively engaged in providing crucial and timely support to Federal, State, and local natural hazards monitoring, analysis, response, and recovery activities. As part of this support, RMGSC has developed the Rapid Data Delivery System (RDDS) to provide emergency and incident response teams with timely access to geospatial data. The RDDS meets these needs by combining a simple webenabled data viewer for the selection and preview of vector and raster geospatial data with an easy to use data ordering form. The RDDS viewer also incorporates geospatial locations for current natural hazard incidents, including wildfires, earthquakes, hurricanes, and volcanoes, allowing incident responders to quickly focus on their area of interest for data selection.

\section{Features}

The RDDS provides a password protected portal for the selection and downloading of vector and raster data that allows users to quickly specify an Area of Interest (AOI) and download the data directly into a Geographic Information System (GIS) application. Through an easy to use popup order form, selected vector layers are zipped together into a compressed file and made available for downloading through an instant notification. A wide-range of raster layers such as orthoimagery, digital raster graphics (USGS topographic maps), and digital elevation and shaded-relief models are also made available through the order form, with the flexibility to re

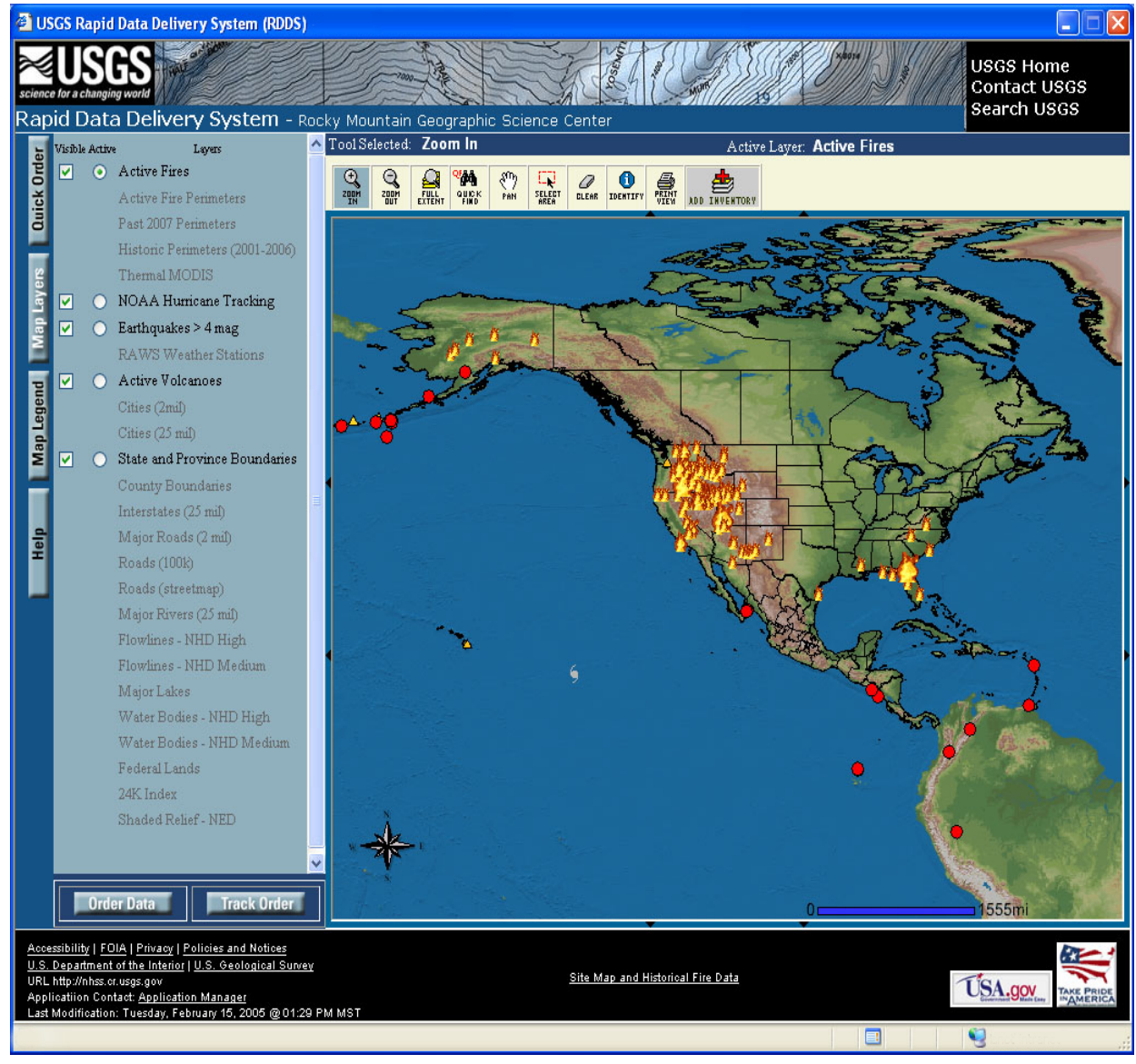

Initial extent showing current natural hazard incidents (above).

project, mosaic, and reformat the data through the desired user selections. Once the raster data has been submitted and processed, an e-mail notification is sent to the user indicating an ftp link from which the data can be downloaded.

The RDDS contains the following geospatial data layers:

\section{Incident Support Layers}

- Active Earthquakes $>4$ magnitude

- Active Volcanoes

- Active Wildfires

- Active Wildfire Perimeters

- Historic Fire Perimeters (2001 - previous year)

- Thermal MODIS

- Remote Automated Weather Stations

\section{Base Map Layers}

- Shaded Relief (color, NED)

- Administrative Data (States, cities, counties)

- Roads with Signs

- Water Bodies and Rivers

- Federal Lands

- 24k Topographic Map Index 


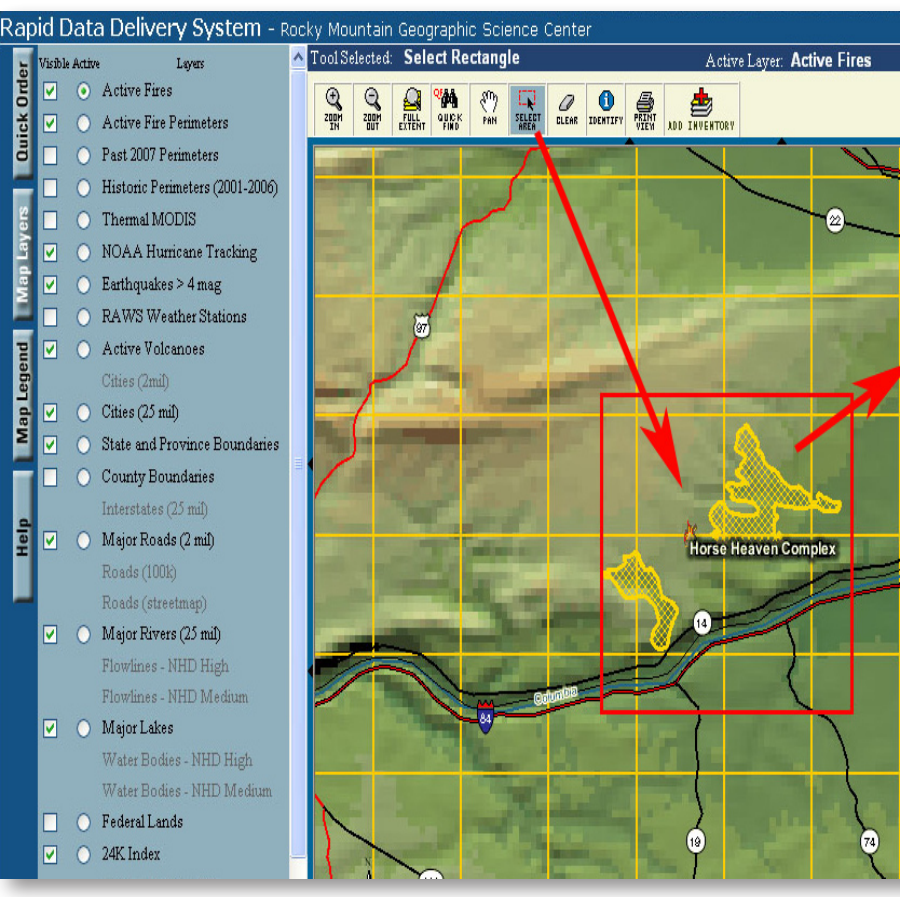

Select the desired area (above), then select the product layers you want using the RDDS Order Form (right).

\section{Downloadable Raster Products}

- Digital Elevation Model

- Shaded Relief

- Orthoimagery ( $1 \mathrm{~m}$ color IR, Natural color IR)

- Digital Raster Graphics (24k topographic maps)

\section{Summary}

The RDDS demonstrates one way in which the RMGSC is committed to providing fast and reliable access to geospatial data in order to assist Federal, State, and local first responders. The ease of use and access to integrated data provided by the RDDS is key to a tactical emergency responder's ability to quickly prepare and respond to national emergencies.

\section{Contact}

Jill Cress, Computer Scientist

United States Geological Survey

Rocky Mountain Geographic Science Center

Denver Federal Center

Lakewood, CO 80225

e-mail: jjcress@usgs.gov 7f USGS Data Delivery System - Microsoff Internet Explorer

\section{Zuses}

\section{Rapid Data Delivery System - Order Form}

$\square$ Click on box to select product(s).

GEOGRAPHIC EXTENT

Upper Lft Lat: $46.023672766470455 \quad$ *ower Rht Lat. 45.6869164094226

Upper Lft Lon: -120.30197031568865 Iower Rht Lon: -119.9406107544726

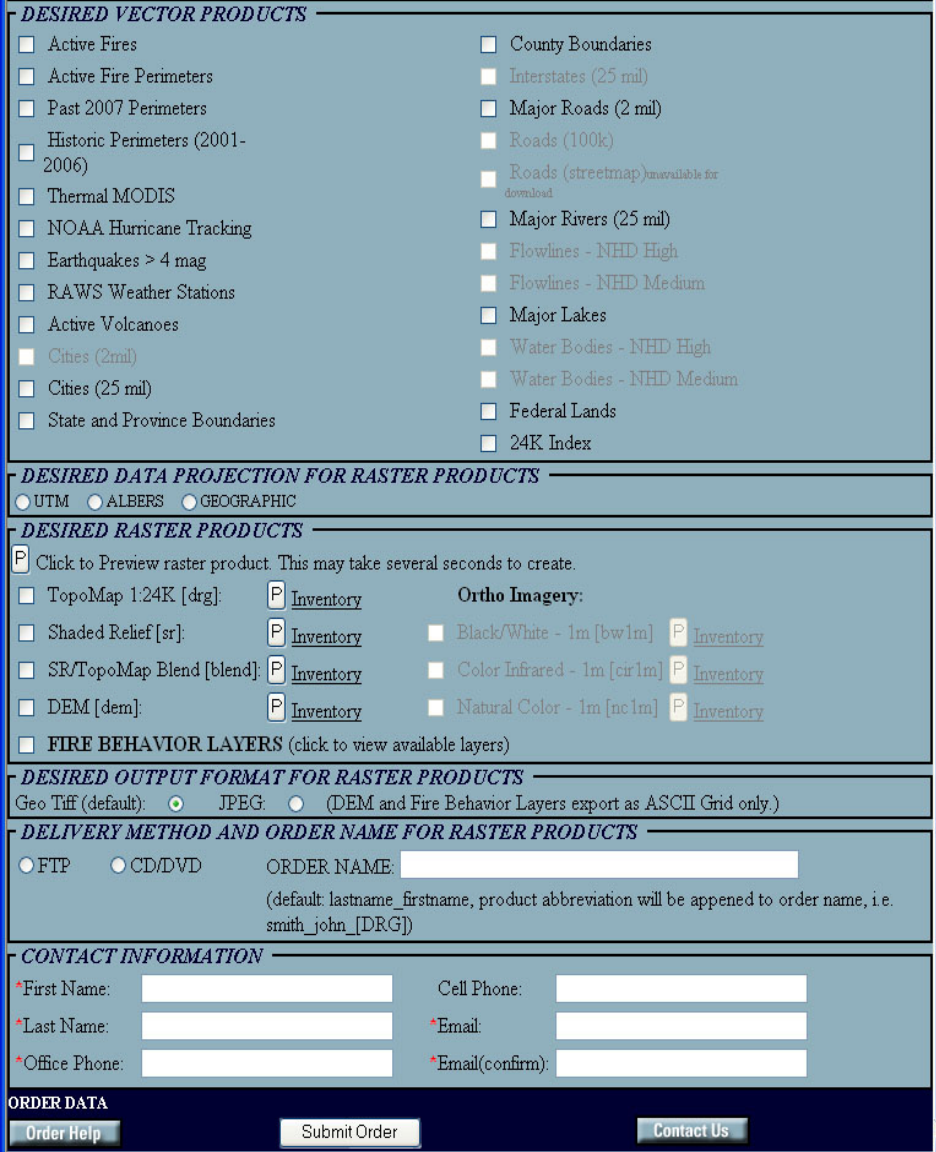

Susan Goplen, Information Technology Specialist United States Geological Survey

Rocky Mountain Geographic Science Center

Denver Federal Center

Lakewood, CO 80225

e-mail:segoplen@usgs.gov

URL: http://rmgsc.cr.usgs.gov/rdds

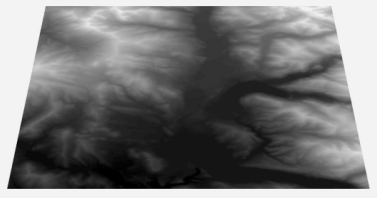

Digital Elevation Model

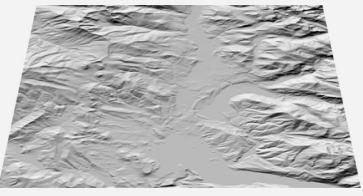

Shaded Relief

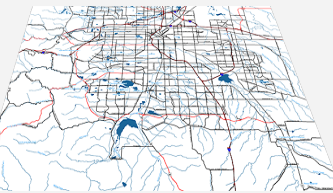

Vector Graphic

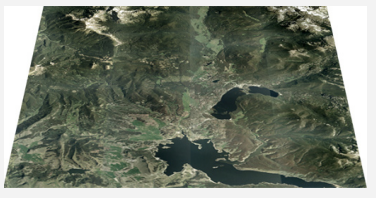

Orthoimagery

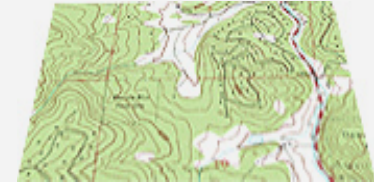

Digital Raster Graphic 